\title{
SOLUTION OF OPERATOR EQUATIONS
}

\author{
"Dr. Emad Abass Kuffi. ** Zainab Fahd Mehuws \\ AL-Qadisiya Unversity, Collage of Education Department of Mathematics \\ "E-mail: emad_Kuffi@yahoo.com, ${ }^{* *}$ E-mail: Zynb_fahad@yahoo.com
}

\section{Abstract}

In this paper, we study and discuss the existence and uniqueness of the solution of the discrete time Sylvester and Lyapunov operator equations, and more general continuous -time Lyapunov operator equations. Also, we study the nature of the solution for these operator equation for special types of operators, as well as the study of the range $\tau_{\mathrm{A}, \mathrm{B}}, \tau_{\mathrm{A}, \text { and }} \tau_{\mathrm{tA}}$ are introduced.

Where,

$$
\begin{aligned}
& \tau_{\mathrm{A}, \mathrm{B}}(\mathrm{x})=\mathrm{AX}-\mathrm{XB}^{-1} \\
& \tau_{\mathrm{A}}(\mathrm{x})=\mathrm{A}^{*} \mathrm{X}-\mathrm{XA}^{-1}, \text { and } \\
& \tau_{\mathrm{tA}}(\mathrm{x})=\mathrm{A}^{*} \mathrm{X}+\mathrm{t} \mathrm{XA}, \mathrm{X} \in \mathrm{B}(\mathrm{H}) .
\end{aligned}
$$

for $\mathrm{A}, \mathrm{B}^{-1}$ and $\mathrm{A}^{-1}$ are fixed operators in $\mathrm{B}(\mathrm{H})$, and $\mathrm{t}$ is any scalar.

Key words: Lyapunov equation, Sylvester Equation, Discrete-time operator equation and continuous-time operator equation

\section{Introducation}

Operator Sylvester equations and Lyapunov equations are very important in control theory and many other branches of engineering,[1] and [4]. The following are some example of operator equations:

- Continuous-and discrete-time Sylvester operator equation :

$\mathrm{AX} \pm \mathrm{XB}=\propto \mathrm{C}$

$\mathrm{AXB} \pm \mathrm{X}=\propto \mathrm{C}$

- Continuous-and discrete -time Lyapaunov operator equation:

$\mathrm{A}^{*} \mathrm{X}+\mathrm{XA}=\propto \mathrm{C}$

$\mathrm{A}^{*} \mathrm{XA}-\mathrm{X}=\propto \mathrm{C}$

- More general Continuous- time Lyapaunov operator equation:

$\mathrm{A}^{*} \mathrm{X}+\mathrm{tXA}=\propto \mathrm{C}$.

where $\mathrm{A}, \mathrm{B}$ and $\mathrm{C}$ are given operators defined on a Hilbert space $\mathrm{H}, \mathrm{X}$ is an operator that must be determined, $\mathrm{t}$ and $\propto$ are any scalars, and $\mathrm{A}^{*}$ is adjoint of $\mathrm{A},[3]$.

In general ,these operator equations may have one solution, infinite set of solutions or no solution. In this paper, existence and uniqueness of the solution of eqs.(2),(4) and (5), when B is an invertible operator in eq.(2), and $\mathrm{A}$ is an invertible operator in eq.(4).

The discrete-time Sylvester equation can be transform to Continuous- time Sylvester equation as follows:
Multiply eq.(2)from the right by $\mathrm{B}^{-1}$, then eq, (2) becomes:

$$
\begin{aligned}
& \mathrm{AXBB}-1 \pm \mathrm{XB}^{-1}=\propto \mathrm{CB}^{-1} \\
& \mathrm{AX} \pm \mathrm{XB}^{-1}=\propto \mathrm{CB}^{-1}
\end{aligned}
$$

Let $\mathrm{CB}^{-1}=\mathrm{W}$, the above equation becomes $\mathrm{AX} \pm \mathrm{XB}^{-1}=\propto \mathrm{W}$

Also, The discrete time-Lyapunov equation can be transform to Continuous- time Lyapunov equation as follows:

Multiply eq.(4)from the right by $\mathrm{A}^{-1}$, then eq, (4) becomes :

$$
\mathrm{A}^{*} \mathrm{XAA}^{-1}-\mathrm{XA}^{-1}=\propto \mathrm{CA}^{-1}
$$

Let $\mathrm{CA}^{-1}=\mathrm{W}$, the equation (7) becomes :

$\mathrm{A}^{*} \mathrm{X}-\mathrm{XA} \mathrm{A}^{-1}=\propto \mathrm{W}$

The Existences and Uniqueness of The Solution of the Discrete-Time Equations

Recall that, the spectrum of the operator $A \equiv \sigma(A)=\{\lambda \in C:(A-\lambda I)$ is not invertible $\}$ and $\mathrm{B}(\mathrm{H})$ is the Banach space of all bounded linear operators defined on the Hilbert space $H,[5]$.

\section{Sylvester-Rosenblum theorem}

If $\mathrm{A}$ and $\mathrm{B}$ are operators in $\mathrm{B}(\mathrm{H})$ (Banach algebra of all bounded linear operators defined on a Hilbert space $\mathrm{H}$ ), such that $\sigma(\mathrm{A}) \cap \sigma(\mathrm{B})=\phi$, then the operator equation A $\mathrm{X}-\mathrm{XB}=\alpha \mathrm{C}$ (continuous-time Syvester operator equation) has a unique solution $\mathrm{X}$, for every operator $\mathrm{C}$.

The following corollaries give the unique solution for the operator eq.(6). 


\section{Corollary}

If $\mathrm{A}$ and $\mathrm{B}$ are operators in $\mathrm{B}(\mathrm{H})$, such that $\sigma(\mathrm{A}) \cap \sigma\left(\mathrm{B}^{-1}\right)=\phi$, then the operator equation $\mathrm{AX}-\mathrm{XB}^{-1}=\alpha \mathrm{W}$, has a unique solution $\mathrm{X}$, for every operator $\mathrm{W} \in \mathrm{B}(\mathrm{H})$.

\section{Corollary}

If $\mathrm{A}$ and $\mathrm{B}$ are operators in $\mathrm{B}(\mathrm{H})$, such that $\sigma(\mathrm{A}) \cap \sigma\left(-\mathrm{B}^{-1}\right)=\phi$, then the operator equation $\mathrm{AX}+\mathrm{XB}^{-1}=\alpha \mathrm{W}$, has a unique solution $\mathrm{X}$, for every operator $\mathrm{W} \in \mathrm{B}(\mathrm{H})$.

\section{Proposition}

Consider eq.(6), if $\sigma(\mathrm{A}) \cap \sigma\left(\mathrm{B}^{-1}\right)=\phi$, then the operator $\left[\begin{array}{cc}A & -\alpha W \\ 0 & B^{-1}\end{array}\right]$ is defined on $\mathrm{H} \oplus \mathrm{H}$ is similar to the operator $\left[\begin{array}{cc}\mathrm{A} & 0 \\ 0 & \mathrm{~B}^{-1}\end{array}\right]$.

\section{Proof:}

Since $\sigma(\mathrm{A}) \cap \sigma\left(\mathrm{B}^{-1}\right)=\phi$, then by SyvesterRosenblum theorem, the equation $\mathrm{AX}-\mathrm{XB}^{-1}=\alpha \mathrm{W}$ has a unique solution $\mathrm{X}$. Also,

$$
\left[\begin{array}{cc}
\mathrm{I} & \mathrm{X} \\
0 & \mathrm{I}
\end{array}\right]\left[\begin{array}{cc}
\mathrm{A} & 0 \\
0 & \mathrm{~B}^{-1}
\end{array}\right]=\left[\begin{array}{cc}
\mathrm{A} & -\alpha \mathrm{W} \\
0 & \mathrm{~B}^{-1}
\end{array}\right]\left[\begin{array}{cc}
\mathrm{I} & \alpha \mathrm{W} \\
0 & \mathrm{I}
\end{array}\right]
$$

But $\left[\begin{array}{cc}\mathrm{I} & \mathrm{X} \\ 0 & \mathrm{I}\end{array}\right]$ is invertible, so $\left[\begin{array}{cc}\mathrm{A} & 0 \\ 0 & \mathrm{~B}^{-1}\end{array}\right]$ is similar to $\left[\begin{array}{cc}\mathrm{A} & -\alpha \mathrm{W} \\ 0 & \mathrm{~B}^{-1}\end{array}\right]$.

\section{Notes:}

(1) The converse of the above proposition is not true in general.

(2) If the condition $\sigma(\mathrm{A}) \bigcap \sigma\left(\mathrm{B}^{-1}\right)=\phi$, fails to satisfied then the operator equation $\mathrm{AX}$ $\mathrm{XB}^{-1}=\alpha \mathrm{W}$, may have no solution .

Now, the following corollary gives the unique solution for the operator eq.(8).

\section{Corollary}

If $A$ an operator, such that $\sigma\left(\mathrm{A}^{*}\right) \cap \sigma\left(\mathrm{A}^{-1}\right)=\phi$, then the eq.(8) has a unique solution $\mathrm{X}$, for every operator $\mathrm{W}$.

\section{Proposition}

Consider eq.(6), if $\sigma\left(\mathrm{A}^{*}\right) \cap \sigma\left(\mathrm{A}^{-1}\right)=\phi$, then the operator $\left[\begin{array}{cc}A^{*} & -\alpha W \\ 0 & A^{-1}\end{array}\right]$ is defined on $\mathrm{H} \oplus \mathrm{H}$ is similar to the operator $\left[\begin{array}{cc}A^{*} & 0 \\ 0 & A^{-1}\end{array}\right]$.

\section{Proof:}

Since $\sigma\left(A^{*}\right) \cap \sigma\left(A^{-1}\right)=\phi$, then by SyvesterRosenblum theorem, eq.(8) has a unique solution. Also,

$$
\left[\begin{array}{cc}
\mathrm{I} & \mathrm{X} \\
0 & \mathrm{I}
\end{array}\right]\left[\begin{array}{cc}
\mathrm{A}^{*} & 0 \\
0 & \mathrm{~A}^{-1}
\end{array}\right]=\left[\begin{array}{cc}
\mathrm{A}^{*} & -\alpha \mathrm{W} \\
0 & \mathrm{~A}^{-1}
\end{array}\right]\left[\begin{array}{cc}
\mathrm{I} & \alpha \mathrm{W} \\
0 & \mathrm{I}
\end{array}\right] .
$$

But $\left[\begin{array}{cc}\mathrm{I} & \mathrm{X} \\ 0 & \mathrm{I}\end{array}\right]$ is invertible, so $\left[\begin{array}{cc}\mathrm{A}^{*} & 0 \\ 0 & \mathrm{~A}^{-1}\end{array}\right]$ is similar to $\left[\begin{array}{cc}A^{*} & -\alpha W \\ 0 & A^{-1}\end{array}\right]$.

\section{Note :}

(1) The converse of the above proposition is not true in general.

(2) If the condition $\sigma\left(\mathrm{A}^{*}\right) \cap \sigma\left(\mathrm{A}^{-1}\right)=\phi$, fails to satisfied then eq.(8) may have one solution, an infinite number of solution or it may have no solution .

\section{The Nature of the Solution for the Discrete -Time Lyapunov Equation .}

In this section, we study the nature of the solution for special types of the linear operator equations ,namely the discrete -time Lyapunov equation.

Recall that, an operator $\mathrm{A}$ is said to be self -adjoint if $\mathrm{A}^{*}=\mathrm{A}$, also an operator $\mathrm{A}$ is said to be skew-adjoint if $A^{*}=-A,[5]$

\section{Remarks}

(1) If $\mathrm{A}, \mathrm{A}^{-1}$, and $\mathrm{W}$ are self -adjoint operators, then eq.(8), may or may not have a solution. Moreover, if it has a solution then it may be non self-adjoint. This remark can easily be observed in matrices.

(2) Consider eq.(8) if $\mathrm{W}$ is self -adjoint operator, then it is not necessarily that $\mathrm{X}=\mathrm{X}^{*}$. 
(3) If $\mathrm{A}, \mathrm{A}^{-1}$, and $\mathrm{W}$ are skew-adjoint operators, then eq.(8) has no solution.

Recall that, an operator $\mathrm{A}$ is said to be normal if $\mathrm{AA}^{*}=\mathrm{A}^{*} \mathrm{~A},[5]$.

\section{Proposition}

(1) If $\mathrm{A}$ is self -adjoint operator, then $\mathrm{A}$ is normal .

(2) If $\mathrm{A}$ is skew -adjoint operator, then $\mathrm{A}$ is normal .

(3) If $\mathrm{A}$ is normal operator and $\mathrm{A}^{-1}$ exist, then $\mathrm{A}^{-1}$ is normal .

\section{Remarks}

Consider eq.(8)

(1) If A and W are normal operators, then the solution $\mathrm{X}$ is not necessarily normal operator.

(2) If $\mathrm{W}$ is normal operator and $\mathrm{A}$ is any operator, then it is not necessarily that the solution $\mathrm{X}$ is normal operator.

Recall that, an operator A is said to be compact incase, given any sequence of vectors $\left\{X_{n}\right\}$ such that $\left\|X_{n}\right\|$ is bounded, $\left\{A_{n}\right\}$ has a convergent subsequence,[5].

\section{$\underline{\text { Remarks (4.3): }}$}

(1) consider eq.(8), if $\mathrm{W}$ is compact operator, then $\mathrm{A}, \mathrm{A}^{-1}$, and $\mathrm{X}$ are not necessarily compact operator.

(2) if $\mathrm{A}$ or $\mathrm{W}$ or $\mathrm{A}^{-1}$ compact operator, and the solution of eq.(8) exists, then it is not necessarily to be compact.

\section{Note:}

Similarly, we can study the nature of the solution for discrete time- Syvester operator equation.

\section{On The Range of $\tau_{\mathrm{A}, \mathrm{B}}$}

In This section, we discuss and study the mapping

$\tau_{\mathrm{A}, \mathrm{B}}: \beta(\mathrm{H}) \rightarrow \beta(\mathrm{H})$, where

$\tau(\mathrm{X})=\tau_{\mathrm{A}, \mathrm{B}}(\mathrm{X})=\mathrm{AX}-\mathrm{XB}^{-1}, \mathrm{X} \in \beta(\mathrm{H})$

and $A, B^{-1}$ are fixed in $\beta(H)$.

Let $\mathrm{R}$ be a ring. A linear(additive ) mapping $\tau$ from $R$ to $R$ is called a derivation, if $\tau(\mathrm{ab})=\mathrm{a} \tau(\mathrm{b})+\tau(\mathrm{a}) \mathrm{b}$, for all $\mathrm{a}, \mathrm{b}$ in $\mathbf{R}$.

It is clear the map $\tau_{A, B}$ is linear map ;in fact

$$
\begin{aligned}
\tau_{\mathrm{A}, \mathrm{B}} & =\left(\alpha \mathrm{X}_{1}+\beta \mathrm{X}_{2}\right)=\mathrm{A}\left(\alpha \mathrm{X}_{1}+\beta \mathrm{X}_{2}\right)-\left(\alpha \mathrm{X}_{1}+\beta \mathrm{X}_{2}\right) \mathrm{B}^{-1} \\
& =\alpha \mathrm{AX}_{1}+\beta \mathrm{AX}_{2}-\alpha \mathrm{X}_{1} \mathrm{~B}^{-1}-\beta \mathrm{X}_{2} \mathrm{~B}^{-1} \\
& =\alpha\left(\mathrm{AX}_{1}-\mathrm{X}_{1} \mathrm{~B}^{-1}\right)+\beta\left(\mathrm{AX}_{2}-\mathrm{X}_{2} \mathrm{~B}^{-1}\right) \\
& =\alpha \tau_{\mathrm{A}, \mathrm{B}}\left(\mathrm{X}_{1}\right)+\beta \tau_{\mathrm{A}, \mathrm{B}}\left(\mathrm{X}_{2}\right), \text { for each scalars } \alpha
\end{aligned}
$$
and $\beta$.

Also, the map $\tau_{\mathrm{A}, \mathrm{B}}$ is bounded, since

$\left\|\tau_{\mathrm{A}, \mathrm{B}}\right\|=\left\|\mathrm{AX}-\mathrm{XB}^{-1}\right\| \leq\|\mathrm{AX}\|+\left\|\mathrm{XB}^{-1}\right\|$

$$
\leq\|\mathrm{X}\|\left[\|\mathrm{A}\|+\left\|\mathrm{B}^{-1}\right\|\right]
$$

But $A, B^{-1} \in \beta(H)$, let $M=\|A\|+\left\|B^{-1}\right\|$, then

$\left\|\tau_{\mathrm{A}, \mathrm{B}}\right\| \leq \mathrm{M}\|\mathrm{X}\|$.

So $\tau_{\mathrm{A}, \mathrm{B}}$ is bounded.

The following remark shows that the mapping $\tau_{\mathrm{A}, \mathrm{B}}$ is not derivation.

\section{Remark}

Since $\tau_{\mathrm{A}, \mathrm{B}}(\mathrm{XY})=\mathrm{A}(\mathrm{XY})-(\mathrm{XY}) \mathrm{B}^{-1}$ for all $X, Y \in \beta(H)$ and $\tau_{A, B}(Y)=X A Y-X Y B^{-1}$. Also, $\tau_{\mathrm{A}, \mathrm{B}}(\mathrm{X}) \mathrm{Y}=\mathrm{AXY}-\mathrm{XB}^{-1} \mathrm{Y}$ then one can deduce that $\tau_{\mathrm{A}, \mathrm{B}}(\mathrm{XY}) \neq \mathrm{X} \tau_{\mathrm{A}, \mathrm{B}}(\mathrm{Y})+\tau_{\mathrm{A}, \mathrm{B}}(\mathrm{X}) \mathrm{Y}$.

Now, let $\mathrm{R}$ be * - ring , i.e , a ring with involution $*$. The linear mapping $\tau$ from $\mathrm{R}$ to $\mathrm{Ris}$ called Jordan $\quad *$ - derivation, if for all $\mathrm{a}, \mathrm{b} \in \mathrm{R}$, $\tau\left(\mathrm{a}^{2}\right)=\mathrm{a} \tau(\mathrm{a})+\tau(\mathrm{a}) \mathrm{a}^{*}$.

Recall that , a Jordan derivation $f: R \rightarrow R$ is defined to be a dditive mapping satisfying $f\left(a^{2}\right)=a f(a)+f(a) a$.

If $\mathrm{R}$ is a ring with trivial involution, $\mathrm{a}^{*}=\mathrm{a}$,then the set of all Jordan $*$-derivations is equal to the set of all Jordan derivations

It is easily seen that the mapping $\tau: \beta(\mathrm{H}) \rightarrow \beta(\mathrm{H})$ defined by

$\tau(\mathrm{X})=\tau_{\mathrm{A}, \mathrm{B}}(\mathrm{X})=\mathrm{AX}-\mathrm{XB}^{-1}$ is not Jordan * -derivation .

Now, we have the following simple proposition:

\section{Proposition}

$$
\alpha \operatorname{Rang}\left(\tau_{\mathrm{A}, \mathrm{B}}\right)=\operatorname{Rang}\left(\tau_{\mathrm{A}, \mathrm{B}}\right)
$$

\section{Proof:}

$$
\text { since } \quad \alpha \quad \operatorname{Rang}\left(\tau_{\mathrm{A}, \mathrm{B}}\right)=\left\{\alpha\left(\quad \mathrm{AX}-\mathrm{XB}^{-1}\right)\right.
$$

$, X \in \beta(H)\}=\left\{A \alpha X-\alpha X^{-1}, X \in \beta(H)\right\}$

Let $\mathrm{X}_{1}=\alpha \mathrm{X}$, then

$\alpha \quad \operatorname{Rang}\left(\tau_{\mathrm{A}, \mathrm{B}}\right)=\left\{\mathrm{AX}_{1}-\mathrm{X}_{1} \mathrm{~B}^{-1} \quad, \mathrm{X}_{1} \in \beta(\mathrm{H}) \quad\right\}=$ $\operatorname{Rang}\left(\tau_{\mathrm{A}, \mathrm{B}}\right)$. 
Remarks

$$
\operatorname{Rang}\left(\tau_{\mathrm{A}, \mathrm{B}}\right)^{*} \neq \operatorname{Rang}\left(\tau_{\mathrm{A}, \mathrm{B}}\right) .
$$

\section{On the Rang of $\tau_{\mathrm{A}}$}

In this section, we discuss and study the map

$$
\begin{gathered}
\tau_{\mathrm{A}}: \beta(\mathrm{H}) \rightarrow \beta(\mathrm{H}), \text { where } \\
\tau(\mathrm{X})=\tau_{\mathrm{A}}(\mathrm{X})=\mathrm{A}^{*} \mathrm{X}-\mathrm{XA}^{-1}, \mathrm{X} \in \beta(\mathrm{H})
\end{gathered}
$$

It is clear that the map $\tau_{\mathrm{A}}$ is a linear map ;in fact

$$
\begin{aligned}
& \tau_{\mathrm{A}}\left(\alpha \mathrm{X}_{1}+\beta \mathrm{X}_{2}\right)=\mathrm{A}^{*}\left(\alpha \mathrm{X}_{1}+\beta \mathrm{X}_{2}\right)-\left(\alpha \mathrm{X}_{1}+\beta \mathrm{X}_{2}\right) \mathrm{A}^{-1} \\
& =\alpha \mathrm{A}^{*} \mathrm{X}_{1}+\beta \mathrm{A}^{*} \mathrm{X}_{2} \beta \mathrm{X}_{2}-\alpha \mathrm{X}_{1} \mathrm{~A}^{-1}-\beta \mathrm{X}_{2} \mathrm{~A}^{-1} \\
& =\alpha\left(\mathrm{A}^{*} \mathrm{X}_{1}-\mathrm{X}_{1} \mathrm{~A}^{-1}\right)+\beta\left(\mathrm{A}^{*} \mathrm{X}_{2}-\mathrm{X}_{2} \mathrm{~A}^{-1}\right) \\
& =\alpha \tau_{\mathrm{A}}\left(\mathrm{X}_{1}\right)+\beta \tau_{\mathrm{A}}\left(\mathrm{X}_{2}\right)
\end{aligned}
$$

Also, the map $\tau_{\mathrm{A}}$ is bounded, since

$\left\|\tau_{\mathrm{A}}\right\|=\left\|\mathrm{A}^{*} \mathrm{X}-\mathrm{XA} \mathrm{A}^{-1}\right\| \leq\left\|\mathrm{A}^{*} \mathrm{X}\right\|+\left\|\mathrm{XA}^{-1}\right\|$

$$
\leq\|\mathrm{X}\|\left[\|\mathrm{A}\|+\left\|\mathrm{A}^{-1}\right\|\right]
$$

But $A, A^{-1} \in \beta(H)$, let $M=\|A\|+\left\|A^{-1}\right\|$, then

$\left\|\tau_{\mathrm{A}}\right\| \leq \mathrm{M}\|\mathrm{X}\|$. So $\tau_{\mathrm{A}}$ is bounded.

The following remark shows that the mapping $\tau_{\mathrm{A}}$ is not derivation.

\section{Remarks}

$$
\tau_{\mathrm{A}}(X Y)=\mathrm{A}^{*}(\mathrm{XY})-(\mathrm{XY}) \mathrm{A}^{-1} \text { for } \mathrm{X}, \mathrm{Y} \in \beta(\mathrm{H})
$$

and $\mathrm{X} \tau_{\mathrm{A}}(\mathrm{Y})=\mathrm{XA}{ }^{*} \mathrm{Y}-\mathrm{XYA} \mathrm{A}^{-1}$.

Also $\tau_{A}(X) Y=A^{*} X Y-X A^{-1} Y$. Then one can deduce that $\tau_{\mathrm{A}}(\mathrm{XY}) \neq \mathrm{X} \tau_{\mathrm{A}}(\mathrm{Y})+\tau_{\mathrm{A}}(\mathrm{X}) \mathrm{Y}$.

It is easily seen that the mapping $\tau_{\mathrm{A}}$ is not Jordan $*$-derivation .

Now, we have the following simple proposition .

\section{Proposition}

$$
\alpha \operatorname{Rang}\left(\tau_{\mathrm{A}}\right)=\operatorname{Rang}\left(\tau_{\mathrm{A}}\right)
$$

\section{Proof:}

Since $\quad \alpha \operatorname{Rang}\left(\tau_{\mathrm{A}}\right)=\left\{\alpha\left(\mathrm{A}^{*} \mathrm{X}-\mathrm{XA}^{-1}\right)\right.$, $\mathrm{X} \in \beta(\mathrm{H})\}=\left\{\mathrm{A}^{*}(\alpha \mathrm{X})-(\alpha \mathrm{X}) \mathrm{A}^{-1}, \mathrm{X} \in \beta(\mathrm{H})\right\}$

Let $X_{1}=\alpha X$, then $\alpha \operatorname{Rang}\left(\tau_{\mathrm{A}, \mathrm{B}}\right)=\left\{\mathrm{A}^{*} \mathrm{X}_{1}-\mathrm{X}_{1} \mathrm{~A}^{-1}, \mathrm{X}_{1} \in \beta(\mathrm{H}) \quad\right\}=$ $\operatorname{Rang}\left(\tau_{\mathrm{A}}\right)$.

\section{Remarks}

$$
\operatorname{Rang}\left(\tau_{\mathrm{A}}\right)^{*} \neq \operatorname{Rang}\left(\tau_{\mathrm{A}}\right) .
$$

\section{More General Continuous-Time Lyapunov Equations}

In this section, we study the nature of the solution of more general continuous-time Lyapunov equations for special types of operations.

Consider the operator equation given by eq.(5). The question now is pertinent does eq.(5) have a solution?

To answer this question, remember the Sylvester - Rosenblum theorem.

According to it, one can prove the following proposition.

\section{Proposition}

Consider the operator equation $\mathrm{A}^{*} \mathrm{X}-\mathrm{tXA}=\alpha \mathrm{C}$, where $\mathrm{A}$ is an operator such that $\sigma\left(\mathrm{A}^{*}\right) \cap \sigma(-\mathrm{tA})=\phi$, for every scalar $\mathrm{t}$, then this equation has a unique solution $\mathrm{X}$, for every operator $\mathrm{C}$ and $\alpha$ is any scalar.

\section{Remark}

If the condition $\sigma\left(\mathrm{A}^{*}\right) \cap \sigma(-\mathrm{tA})=\phi$, fails to be satisfied then eq.(5) may have an infinite number of solutions or may not.

Now, we study the nature of the solution of eq.(5) for special types of operators.

\section{Remarks}

If $\mathrm{A}$ and $\mathrm{C}$ are self - adjoint operators, $\mathrm{t} \in \mathrm{C}$ then eq.(5) may or may not have a solution. Moreover, if it has a solution then it may be non self-adjoint.

This remark can easily be observed in matrices.

\section{Remark}

Consider eq.(5).If $\mathrm{A}$ and $\mathrm{C}$ are self-adjoint operators then this equation has no solution. This remark can easily be verified.

\section{Remark}

If $\mathrm{A}$ and $\mathrm{C}$ are skew - adjoint operators, then eq.(5) has no solution for every $t$.

The following remark illustrates that the solution of eq.(5) is not necessarily a normal operator in case the known operators $\mathrm{A}$ and $\mathrm{C}$ in the equation are normal.

\section{Remark}


Consider eq.(5), while its solution exist. If $\mathrm{A}$ and $\mathrm{C}$ are normal operators then this solution is not necessarily normal.

This remark can easily be seen in matrices

The following remark shows that the solution $\mathrm{X}$ in eq.(5) is not necessarily a compact operator in case $\mathrm{A}$ is a compact operator for every $t$.

\section{Remark}

Consider eq.(5), while its solution exist. If $\mathrm{A}$ is a compact operator then $\mathrm{A}^{*}$ is also, thus tXA and $A^{*} X$ are also for every value of $t$. Therefore, $\mathrm{C}$ is also a compact operator. But the solution $\mathrm{X}$ of this equation needs not be compact.

The following proposition can easily be verified by the properties of compact operators.

\section{Proposition}

Consider eq.(5) while its solution exist. If $\mathrm{A}$ is a compact operator then $\mathrm{A}^{*}$ is also, thus tXA and $A^{*} X$ is also for each $X \in \beta(H)$. Therefore $\mathrm{C}$ is also a compact operator. But the solution of this equation needs not be compact .

\section{On the Range of $\tau_{\mathrm{tA}}$}

In this section, we discuss and study the range of $\tau_{\mathrm{tA}}$, where

$\tau(X)=\tau_{\mathrm{tA}}(\mathrm{X})=\mathrm{A}^{*} \mathrm{X}+\mathrm{t} \mathrm{XA}, \mathrm{X} \in \beta(\mathrm{H})$.

where $A$ is fixed in $\beta(H), t$ is any scalar.

It is clearly that the map $\tau_{\mathrm{tA}}$ is a linear map ;in fact

$$
\begin{aligned}
\tau_{\mathrm{tA}}\left(\alpha \mathrm{X}_{1}+\beta \mathrm{X}_{2}\right) & =\mathrm{A}^{*}\left(\alpha \mathrm{X}_{1}+\beta \mathrm{X}_{2}\right)+\mathrm{t}\left(\alpha \mathrm{X}_{1}+\beta \mathrm{X}_{2}\right) \mathrm{A} \\
& =\alpha \tau_{\mathrm{tA}}\left(\mathrm{X}_{1}\right)+\beta \tau_{\mathrm{tA}}\left(\mathrm{X}_{2}\right)
\end{aligned}
$$

Also, the map $\tau_{\mathrm{tA}}$ is bounded, since

$$
\left\|\tau_{\mathrm{tA}}\right\|=\left\|\mathrm{A}^{*} \mathrm{X}+\mathrm{tXA}\right\| \leq\left\|\mathrm{A}^{*} \mathrm{X}\right\|+|\mathrm{t}|\|\mathrm{XA}\| \leq
$$

$$
\left.\|X\|\left[\left\|A^{*}\right\|+|t|\right)\|A\|\right] \text {. }
$$

But $\mathrm{A}, \mathrm{B} \in \beta(\mathrm{H})$ and $\left\|\mathrm{A}^{*}\right\|=\|\mathrm{A}\|$, thus $\left\|\tau_{\mathrm{tA}}\right\| \leq \mathrm{M}\|\mathrm{X}\|$, where

$\mathrm{M}=(1+|\mathrm{t}|)\|\mathrm{A}\|$, so $\tau_{\mathrm{tA}}$ is bounded.

The following remark shows that the mapping $\tau_{\mathrm{tA}}$ is not a derivation .

\section{Remark}

Since $\tau_{\mathrm{tA}}(X Y)=A^{*}(X Y)+t(X Y) A$ for all $\mathrm{X}, \mathrm{Y} \in \beta(\mathrm{H})$ and $\mathrm{X} \tau_{\mathrm{tA}}(\mathrm{Y})=\mathrm{XA}{ }^{*} \mathrm{Y}+\mathrm{tXYA}$. Also
$\tau_{\mathrm{tA}}(\mathrm{X}) \mathrm{Y}=\mathrm{A}^{*} \mathrm{XY}+\mathrm{t} \mathrm{XAY}$. Then one can deduce that $\tau_{\mathrm{tA}}(\mathrm{XY}) \neq \mathrm{X} \tau_{\mathrm{tA}}(\mathrm{Y})+\tau_{\mathrm{tA}}(\mathrm{X}) \mathrm{Y}$.

It is easily seen that the mapping $\tau_{\mathrm{tA}}$ is not Jordan *-derivation.

Now, we have the following simple Proposition.

\section{Proposition}

$\alpha \operatorname{Rang}\left(\tau_{\mathrm{tA}}\right)=\operatorname{Rang}\left(\tau_{\mathrm{tA}}\right)$.

\section{Proof:}

$$
\begin{aligned}
\alpha \operatorname{Rang}\left(\tau_{\mathrm{tA}}\right) & =\left\{\alpha\left(\mathrm{A}^{*} \mathrm{X}+\mathrm{tXA}\right), \mathrm{X} \in \beta(\mathrm{H})\right\} \\
& =\left\{\mathrm{A}^{*} \alpha \mathrm{X}+\mathrm{t} \alpha \mathrm{XA}, \mathrm{X} \in \beta(\mathrm{H})\right\}
\end{aligned}
$$

Let $X_{1}=\alpha X$, then:

$$
\alpha \operatorname{Rang}\left(\tau_{\mathrm{tA}}\right)=\left\{\mathrm{A}^{*} \mathrm{X}_{1}+\mathrm{t} \mathrm{X}_{1} \mathrm{~A}, \mathrm{X}_{1} \in \beta(\mathrm{H})\right\} .
$$

\section{References}

[1] Bhatia , R . and Sner,L,"Positive Linear Maps and The Lyapunov Equation ", operator THEORY: Advances And Applications Vol. 130, ,(2001),pp.107120.

[2] Bhatia , R . and Rosenthal ,P. "How and Why To Solve the Operator Equation $\mathrm{AX}-\mathrm{XB}=\mathrm{Y}$ “ Bull- London Math. Soc. , Vol. 39 ,(1997),pp.1-12.

[3] Vasile Sima, "Computational Experience in Solving Large Linear Matrix Equations for Automatic Control", (2004).

[4] Sorensen D.C. and Zhon Y., "Direct Methods for Matrix Sylvester and Lyapunov Equations", (2003).

[5] Sterling K. Berberian, "Introduction to Hilbert Space", Chelsea Publishing Company, New york, N.Y., (1976).

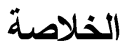

$$
\begin{aligned}
& \text { في هذا البحث درسنا وناقشنا و وجود و وحدانية الحل } \\
& \text { لمعادلات ليبانوف وسلفستر المتقطعة المؤثرة وكذلك } \\
& \text { معادلات ليبانوف المستمرة المؤثرة الأكثر عمومية. كما } \\
& \text { درس البحث ايضاً طبية الحل لتلك المعادلات المؤثرة }
\end{aligned}
$$

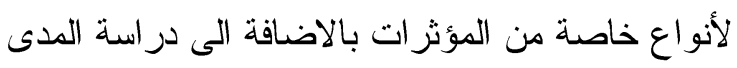

$$
\begin{aligned}
& \tau_{\mathrm{tA}} \triangleleft \tau_{\mathrm{A}^{6}} \tau_{\mathrm{A}, \mathrm{B}} \\
& \tau_{\mathrm{A}, \mathrm{B}}(\mathrm{X})=\mathrm{AX}-\mathrm{XB}^{-1} \\
& \tau_{\mathrm{A}}(\mathrm{x})=\mathrm{A}^{*} \mathrm{X}-\mathrm{XA}^{-1} \text {, and } \\
& \tau_{\mathrm{tA}}(\mathrm{x})=\mathrm{A}^{*} \mathrm{X}+\mathrm{t} \mathrm{XA}, \mathrm{X} \in \mathrm{B}(\mathrm{H}) \text {. }
\end{aligned}
$$


لكل A مؤثرات مثبتة في B(H) أي ثابت

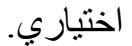

